\title{
Using Multisensor SAR Datasets to Monitor Land Subsidence in Los Angeles from 2003 to 2017
}

\author{
Bo Hu (iD, Xiongle Chen, and Xingfu Zhang $(1)$ \\ Guangdong University of Technology, Guangzhou, China \\ Correspondence should be addressed to Bo Hu; hubo@asch.whigg.ac.cn
}

Received 12 July 2018; Revised 6 November 2018; Accepted 27 November 2018; Published 27 February 2019

Guest Editor: Sang-Hoon Hong

Copyright () 2019 Bo Hu et al. This is an open access article distributed under the Creative Commons Attribution License, which permits unrestricted use, distribution, and reproduction in any medium, provided the original work is properly cited.

\begin{abstract}
Los Angeles has undergone tremendous deformations over the past few decades, mainly due to human factors such as natural disasters and earthquakes, urban construction, overexploitation of groundwater, and oil extraction. The purpose of this study is to map the temporal and spatial variations of land subsidence in Los Angeles and to use the improved SBAS (small baseline subset) technique and multisensor SAR datasets to analyze the causes of deformations in this area from October 2003 to October 2017. At the same time, the deformation results of SBAS inversion are compared with the GPS measurements and the multisensor SAR dataset deformation, and the results are highly consistent. During the period from 2003 to 2017, there were several subsidence regions and one uplift region in Los Angeles. The cumulative subsidence was $-266.8 \mathrm{~mm}$ at the maximum, and the average annual subsidence velocity was $-19 \mathrm{~mm} / \mathrm{yr}$, which was mainly caused by groundwater overexploitation. The maximum amount of accumulated lift is $+104.8 \mathrm{~mm}$, and the average annual lifting velocity can reach $+7.5 \mathrm{~mm} / \mathrm{yr}$. Our results have very strong practical application value and can provide a significant basis for local government services in disaster prevention and mitigation decision-making.
\end{abstract}

\section{Introduction}

The Los Angeles area, located in Southern California, is one of the most developed and densely populated areas in the United States. At the same time, it is located in the world's largest seismic zone, the Pacific Rim seismic zone. What is more, there are many faults distributed. On January 17, 1994, a 6.7 M earthquake struck the Los Angeles area and caused more than 1500 aftershocks [1]. 62 people died, more than 9000 people were injured, 25,000 were homeless, transportation facilities were seriously damaged, and cumulative economic losses amounted to more than 30 billion U.S. dollars. So far, many earthquakes have occurred in the area.

Los Angeles is a Mediterranean climate zone that is generally dry throughout the year and has an annual precipitation of only $378 \mathrm{~mm}$, but there is slightly more rainfall in winter. Since only a small amount of rainfall can penetrate the groundwater and many people continue to extract groundwater, it eventually leads to an imbalance in groundwater circulation. At the same time, the fault can prevent the movement of groundwater to a certain extent and the land subsidence, and uplift of the local area are caused. In the first half of the 20th century, scientists from the US Geological Survey recorded large-scale land subsidence for the first time and found that most of the subsidence was caused by overexploitation of groundwater. Later, the government tried to restore groundwater aquifers by transferring abundant water from the north to the dry south, thereby reducing the amount of subsidence. Regrettably, the subsidence is still continuing, even surpassing the historical high of $30 \mathrm{~cm} /$ year.

Whether the earthquake or groundwater exploitation causes surface changes, it will cause huge losses to infrastructure, bridges, roads, underground pipelines, and other infrastructure. At present, the problem of land subsidence has been spread throughout China. Serious land subsidence occurred in cities such as Beijing, Shanghai, and Taiyuan, causing huge economic losses. The continued overexploitation of groundwater is the main reason for the rapid subsidence of the ground in Beijing. At present, there are two main subsidence centers in the north and south, and the surface continues to settle at a rate of $30-60 \mathrm{~mm} / \mathrm{yr}$ [2]. 


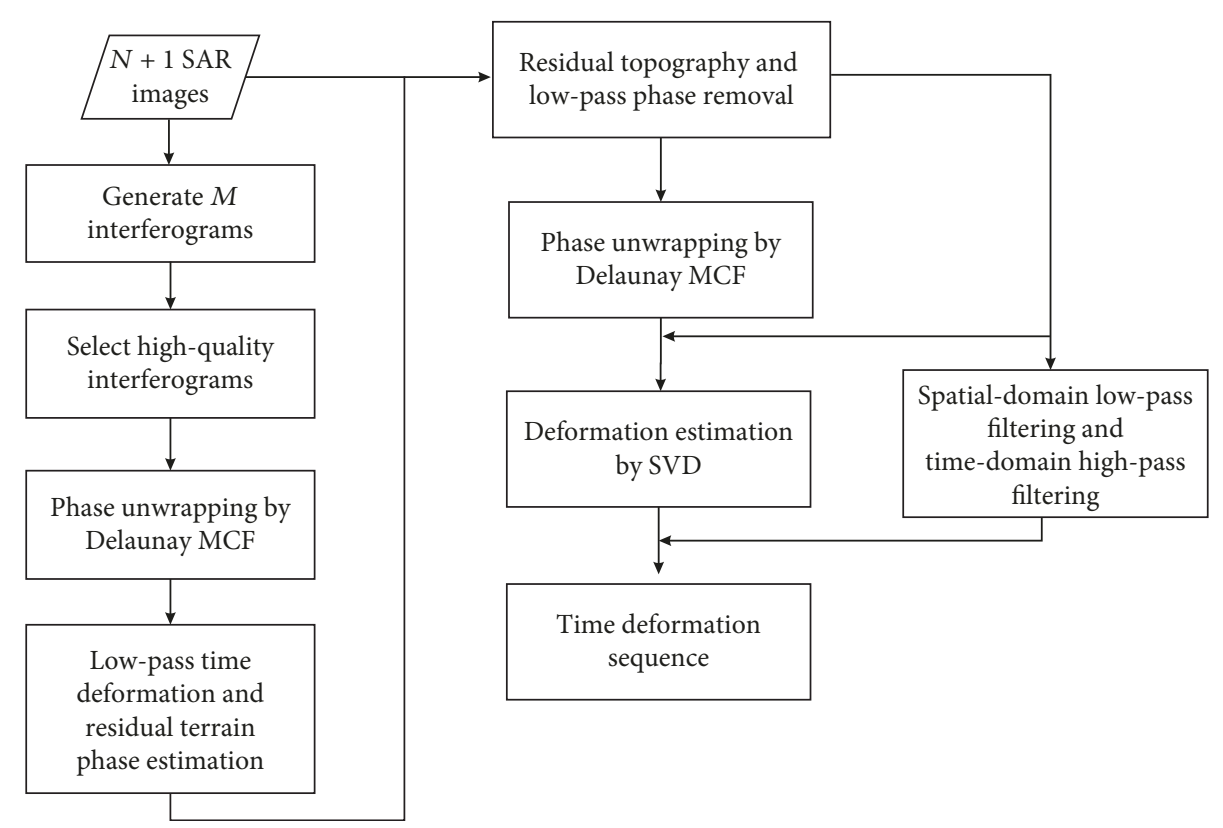

FIGURE 1: SBAS processing flow.

Therefore, it is of great significance to carry out long-span, high-precision, short-period, and large-coverage monitoring to provide the latest subsidence information to urban monitoring in urban construction.

Compared with conventional measurement technology, InSAR, as a kind of space observation technology, has been widely used in earthquake monitoring and urban subsidence monitoring, because of its all-weather, high-precision, wide monitoring area and low cost [3]. In order to solve the problem that conventional InSAR technology is limited by spatiotemporal and atmospheric delays, researchers have proposed time series InSAR technology, such as Permanent Scatterer (PS) $[4,5]$ and SBAS [6]. SBAS solves all the interference pairs that satisfy the baseline requirements and uses the singular value decomposition (SVD) method to get the minimum solution. It can monitor long-term surface deformation and overcome the effects of temporal and spatial irregularities and atmospheric delays, thus improving the monitoring accuracy to the millimeter level. Its ability to detect slow deformations accumulated over a long period of time shows great potential.

Many papers have been published on the monitoring of InSAR technology in Los Angeles [7-11]. However, the above papers only focus on deformation monitoring in the short term, without long-term monitoring and analysis. More than one hundred SAR images, including Envisat ASAR, ALOS-1 Palsar, TerraSAR-X, and Sentinel-1 datasets, are involved to analyze the characteristics of ground deformation from 2003 to 2017 by using the SBAS technique. Our results have a very strong practical application value which can quickly monitor the deformation anomaly area and provide significant data to serve the decision-making of disaster prevention and mitigation for the local government.

\section{Methodology}

SBAS is a newly developed MT-InSAR method, which was first proposed by researchers such as Lanari et al. [12, 13]. This paper uses the improved SBAS method for processing. The adaptive filtering method is used to improve the quality of the interferogram. The high quality interferogram is selected to remove the image with poor interference quality, and the Delaunay Minimum Cost Stream (Delaunay MCF) is used to improve the robustness of the algorithm. SBAS combines the image pairs of a small baseline to generate a series of interferograms with different master image time series. It can increase the time sampling rate by using all the data included in different small baseline subsets to solve the problem that the temporal sampling is too sparse. Then, using the singular value decomposition (SVD) method of the matrix, multiple small baseline subsets are combined to solve the least-quadratic least-squares solution [14]. The frequency characteristics of the delay phase due to atmospheric delay are different in the time domain and the spatial domain. The atmospheric phase is spatially correlated and appears as a low frequency signal in the spatial domain. In the time domain, the atmospheric disturbances during image acquisition are random, and the atmospheric phase is irrelevant in the time domain, which is represented by high frequency signals. Therefore, the effects of atmospheric delay are effectively improved by high-pass filtering in the time domain and low-pass filtering in the spatial domain. Finally, the deformation sequence covering the entire observation time and the land subsidence rate were obtained. The basic principle of SBAS:

(1) first, obtain $N+1$ SAR images of the same area, in order of acquisition time $t_{0}, \ldots, t_{N}$. At the same time, 


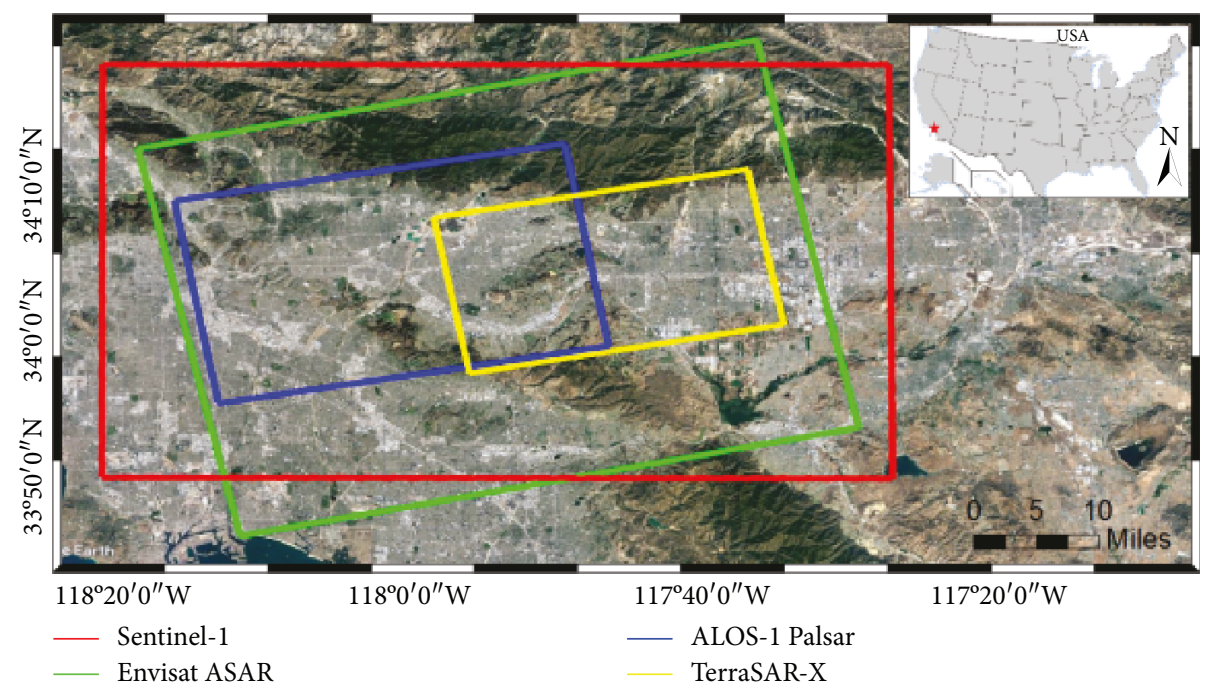

FIGURE 2: The coverage of the radar image data used in this research overlaid on the Los Angeles map.

it is assumed that each image can interfere with at least another image. Select one of the images as the master image and interfere with the rest of the SAR images to form a small baseline subset. Then, the $N+1$ SAR image can generate $M$ multiview interferograms with $N+1$ subsets. $M$ is the sum of the number of interference pairs in each small baseline subset, and the formation of interferograms between SAR images is determined by the time baseline and the spatial baseline

(2) taking the images $t_{A}$ and $t_{B}$ as examples, the $j$-th differential interferogram is generated from the SAR images acquired from the slave image $t_{A}$ and the master image $t_{B}\left(t_{A}>t_{B}\right)$, the interference phase of the pixel with the azimuth coordinate $x$ and the range coordinater can be rewritten as

$$
\begin{aligned}
\delta \phi_{j}(x, r)= & \phi_{B}(x, r)-\phi_{A}(x, r) \\
\approx & \frac{4 \pi}{\lambda}\left[d\left(t_{B}, x, r\right)-d\left(t_{A}, x, r\right)\right]+\Delta \Phi_{\text {topo }}(x, r) \\
& +\Delta \Phi_{\mathrm{APS}}^{j}\left(t_{B}, t_{A}, x, r\right)+\Delta \Phi_{\text {noise }}^{j}(x, r) .
\end{aligned}
$$

In the formula, $j \in(, \cdots, M), \lambda$ is the center wavelength of the signal; $d\left(t_{B}, x, r\right)$ and $d\left(t_{A}, x, r\right)$ are $t_{B}$ and $t_{A}$ moments relative to the accumulated visual variables of the radar line of sight $d\left(t_{0}, x, r\right)=0$; $\Delta \Phi_{\text {topo }}^{j}(x, r)$ denotes the residual topographic phase in the differential interferogram; assuming that the DEM introduced in the differential interference process is of high precision, most of the terrain phases can be removed and the residual topographic information in the differential interferogram is small and can be ignored in the subsidence process; $\Delta \Phi_{\mathrm{APS}}^{j}\left(t_{B}, t_{A}, x, r\right)$ is the atmospheric delay phase; and $\Delta \Phi_{\text {noise }}^{j}(x, r)$ denotes decoherence noise (such as system thermal noise). If we do not consider the atmospheric delay phase, residual topography phase, and noise phase, (1) can be simplified as

$$
\begin{aligned}
\delta \phi_{j}(x, r) & =\phi_{B}(x, r)-\phi_{A}(x, r) \\
& \approx \frac{4 \pi}{\lambda}\left[d\left(t_{B}, x, r\right)-d\left(t_{A}, x, r\right)\right] .
\end{aligned}
$$

(3) in order to obtain a physically meaningful settling sequence, the phase in equation (2) is expressed as the product of the average phase velocity and time between the two acquisition times:

$$
v_{j}=\frac{\Phi_{j}-\Phi_{j-1}}{t_{j}-t_{j-1}} .
$$

The phase value of the $j$-th interferogram can be rewritten as

$$
\sum_{k=t_{A, j}+1}^{t_{B}, j}\left(t_{k}-t_{k-1}\right) v_{k}=\delta \phi_{j} .
$$

Immediately the integration of speed at each time interval between master image and slave image intervals. Written in matrix form:

$$
B v=\delta \phi,
$$

Equation (5) is a matrix of $M * N$. Since the multiprimary image strategy is adopted for the differential interferogram of the small baseline subset, the matrix $B$ is prone to rank loss. By using the SVD method, the generalized inverse matrix of matrix $B$ can be obtained. And then the minimum norm solution of the data vector can be obtained. Finally, the integral of the velocity in each time period can obtain the 
TABle 1

(a) Basic parameters of Envisat ASAR dataset

\begin{tabular}{|c|c|c|c|}
\hline No. & Date & Polarization & Baseline (m) \\
\hline 1 & 2003-10-29 & VV & -213 \\
\hline 2 & 2004-06-30 & VV & 621 \\
\hline 3 & 2004-09-08 & VV & -148 \\
\hline 4 & 2004-11-17 & VV & 366 \\
\hline 5 & 2004-12-22 & VV & 619 \\
\hline 6 & 2005-01-26 & VV & -428 \\
\hline 7 & 2005-03-02 & VV & 490 \\
\hline 8 & 2005-05-11 & VV & -683 \\
\hline 9 & 2005-06-15 & VV & 73 \\
\hline 10 & 2005-07-20 & VV & -486 \\
\hline 11 & 2005-09-28 & VV & -628 \\
\hline 12 & $2005-12-07$ & VV & 676 \\
\hline 13 & 2006-01-11 & VV & -212 \\
\hline 14 & 2006-02-15 & VV & 397 \\
\hline 15 & 2006-03-22 & VV & 770 \\
\hline 16 & 2006-04-26 & VV & -713 \\
\hline 17 & 2006-05-31 & VV & 673 \\
\hline 18 & 2006-10-18 & VV & -281 \\
\hline 19 & 2006-11-22 & VV & 531 \\
\hline 20 & $2006-12-27$ & VV & 295 \\
\hline 21 & 2007-07-25 & VV & -11 \\
\hline 22 & 2007-08-29 & VV & 300 \\
\hline 23 & 2007-10-03 & VV & -166 \\
\hline 24 & 2007-11-07 & VV & 0 \\
\hline 25 & $2007-12-12$ & VV & -332 \\
\hline 26 & 2008-01-16 & VV & 99 \\
\hline 27 & 2008-02-20 & VV & -219 \\
\hline 28 & 2008-03-26 & VV & 180 \\
\hline 29 & 2008-04-30 & VV & -92 \\
\hline 30 & 2008-06-04 & VV & -73 \\
\hline 31 & 2008-07-09 & VV & -149 \\
\hline 32 & $2008-08-13$ & VV & 79 \\
\hline 33 & 2008-09-17 & VV & -231 \\
\hline 34 & 2009-02-04 & VV & -273 \\
\hline
\end{tabular}

(b) Basic parameters of ALOS-1 Palsar dataset

\begin{tabular}{lccc}
\hline No. & Date & Polarization & Baseline $(\mathrm{m})$ \\
\hline 1 & $2006-06-30$ & $\mathrm{HH}$ & -3053 \\
2 & $2006-08-15$ & $\mathrm{HH}$ & -177 \\
3 & $2006-09-30$ & $\mathrm{HH}$ & -316 \\
4 & $2006-11-15$ & $\mathrm{HH}$ & 454 \\
5 & $2006-12-31$ & $\mathrm{HH}$ & -1372 \\
6 & $2007-02-15$ & $\mathrm{HH}$ & 324 \\
7 & $2007-05-18$ & $\mathrm{HH}$ & 518 \\
8 & $2007-07-03$ & $\mathrm{HH}$ & 883 \\
9 & $2007-08-18$ & $\mathrm{HH}$ & 1101 \\
\hline
\end{tabular}

Table 1: Continued.

\begin{tabular}{|c|c|c|c|}
\hline No. & Date & Polarization & Baseline (m) \\
\hline 10 & 2007-10-03 & $\mathrm{HH}$ & 1257 \\
\hline 11 & 2007-11-18 & $\mathrm{HH}$ & 1640 \\
\hline 12 & 2008-01-03 & $\mathrm{HH}$ & 1575 \\
\hline 13 & $2008-02-18$ & $\mathrm{HH}$ & 2506 \\
\hline 14 & 2008-04-04 & $\mathrm{HH}$ & 2836 \\
\hline 15 & $2008-05-20$ & $\mathrm{HH}$ & 2731 \\
\hline 16 & 2008-07-05 & $\mathrm{HH}$ & 0 \\
\hline 17 & $2008-08-20$ & $\mathrm{HH}$ & -2469 \\
\hline 18 & 2008-10-05 & $\mathrm{HH}$ & -1589 \\
\hline 19 & $2008-11-20$ & $\mathrm{HH}$ & -1261 \\
\hline 20 & 2009-01-05 & $\mathrm{HH}$ & -992 \\
\hline 21 & 2009-02-20 & $\mathrm{HH}$ & -671 \\
\hline 22 & 2009-04-07 & $\mathrm{HH}$ & -115 \\
\hline 23 & 2009-07-08 & $\mathrm{HH}$ & -904 \\
\hline 24 & $2009-08-23$ & $\mathrm{HH}$ & 349 \\
\hline 25 & 2009-10-08 & $\mathrm{HH}$ & 626 \\
\hline 26 & 2010-01-08 & $\mathrm{HH}$ & 1011 \\
\hline 27 & $2010-02-23$ & $\mathrm{HH}$ & 1525 \\
\hline 28 & 2010-04-10 & $\mathrm{HH}$ & 1751 \\
\hline 29 & $2010-05-26$ & $\mathrm{HH}$ & 1646 \\
\hline 30 & 2010-07-11 & $\mathrm{HH}$ & 1703 \\
\hline 31 & 2010-10-11 & $\mathrm{HH}$ & 2443 \\
\hline 32 & 2010-11-26 & $\mathrm{HH}$ & 2529 \\
\hline 33 & 2011-01-11 & $\mathrm{HH}$ & 2850 \\
\hline 34 & 2011-02-26 & $\mathrm{HH}$ & 3446 \\
\hline
\end{tabular}

(c) Basic parameters of TerraSAR-X dataset

\begin{tabular}{lccc}
\hline No. & Date & Polarization & Baseline $(\mathrm{m})$ \\
\hline 1 & $2011-03-05$ & $\mathrm{HH}$ & 208 \\
2 & $2011-06-12$ & $\mathrm{HH}$ & 356 \\
3 & $2011-09-19$ & $\mathrm{HH}$ & 508 \\
4 & $2011-10-11$ & $\mathrm{HH}$ & 151 \\
5 & $2011-12-16$ & $\mathrm{HH}$ & 77 \\
6 & $2012-02-20$ & $\mathrm{HH}$ & 321 \\
7 & $2012-04-15$ & $\mathrm{HH}$ & 746 \\
8 & $2012-07-01$ & $\mathrm{HH}$ & 435 \\
9 & $2012-09-27$ & $\mathrm{HH}$ & 383 \\
10 & $2013-01-15$ & $\mathrm{HH}$ & -66 \\
11 & $2013-06-07$ & $\mathrm{HH}$ & 323 \\
12 & $2013-07-21$ & $\mathrm{HH}$ & 149 \\
13 & $2013-08-12$ & $\mathrm{HH}$ & -72 \\
14 & $2013-10-28$ & $\mathrm{HH}$ & -130 \\
15 & $2013-12-11$ & $\mathrm{HH}$ & 10 \\
16 & $2014-01-13$ & $\mathrm{HH}$ & 49 \\
17 & $2014-03-09$ & $\mathrm{HH}$ & 92 \\
18 & $2014-04-22$ & $\mathrm{HH}$ & 0 \\
19 & $2014-06-27$ & $\mathrm{HH}$ & 443 \\
20 & $2014-07-19$ & $\mathrm{HH}$ & 404 \\
\hline
\end{tabular}


TABLe 1: Continued.

\begin{tabular}{lccc}
\hline No. & Date & Polarization & Baseline $(\mathrm{m})$ \\
\hline 21 & $2014-08-10$ & HH & 275 \\
22 & $2014-10-26$ & HH & 60 \\
23 & $2015-01-22$ & HH & 283 \\
24 & $2015-04-09$ & HH & -132 \\
25 & $2015-06-03$ & HH & -82 \\
26 & $2015-08-19$ & HH & 95 \\
27 & $2015-10-02$ & HH & -78 \\
28 & $2015-12-07$ & HH & 55 \\
\hline
\end{tabular}

(d) Basic parameters of Sentinel-1 dataset

\begin{tabular}{|c|c|c|c|}
\hline No. & Date & Polarization & Baseline (m) \\
\hline 1 & $2015-01-26$ & VV & 28 \\
\hline 2 & 2015-05-14 & VV & -123 \\
\hline 3 & $2015-06-07$ & VV & 32 \\
\hline 4 & 2015-07-01 & VV & 112 \\
\hline 5 & $2015-08-18$ & VV & -46 \\
\hline 6 & 2015-09-11 & VV & -16 \\
\hline 7 & $2015-10-05$ & VV & -53 \\
\hline 8 & $2015-11-22$ & VV & -14 \\
\hline 9 & $2015-12-16$ & VV & -35 \\
\hline 10 & 2016-01-09 & VV & 59 \\
\hline 11 & 2016-02-02 & VV & -25 \\
\hline 12 & 2016-03-09 & VV & 0 \\
\hline 13 & 2016-04-02 & VV & -16 \\
\hline 14 & 2016-05-08 & VV & 16 \\
\hline 15 & 2016-06-01 & VV & 3 \\
\hline 16 & 2016-07-19 & VV & -20 \\
\hline 17 & 2016-08-12 & VV & -66 \\
\hline 18 & 2016-09-05 & VV & -54 \\
\hline 19 & $2016-10-11$ & VV & 12 \\
\hline 20 & 2016-11-04 & VV & 35 \\
\hline 21 & $2016-12-10$ & VV & 7 \\
\hline 22 & 2017-01-03 & VV & 15 \\
\hline 23 & 2017-02-08 & VV & 56 \\
\hline 24 & 2017-03-04 & VV & -124 \\
\hline 25 & 2017-05-03 & VV & 10 \\
\hline 26 & 2017-06-08 & VV & 48 \\
\hline 27 & 2017-07-14 & VV & -65 \\
\hline 28 & 2017-08-07 & VV & 33 \\
\hline 29 & 2017-09-12 & VV & -19 \\
\hline 30 & $2017-10-18$ & $\mathrm{VV}$ & -12 \\
\hline
\end{tabular}

deformation variables of each time period. The SBAS timing processing data flow is shown in Figure 1.

\section{Study Area and Datasets}

The research area is located in Los Angeles, Southern California. It is one of the core areas of the United States. It contains dense high-rise buildings, high population density, and convenient transportation. The scope of this study is shown in Figure 2.

In order to study the surface changes in Los Angeles over the past 14 years, SAR images of four different satellites were used. The Envisat ASAR images were acquired from 2003 to 2009 , and the specific parameter information is shown in Table 1(a). The ALOS-1 Palsar images were acquired from 2006 to 2011, and the specific parameter information is shown in Table $1(\mathrm{~b})$. The TerraSAR-X images were acquired from 2011 to 2015, and the specific parameter information is shown in Table 1(c). The Sentinel-1 images were acquired from 2015 to 2017, and the specific parameter information is shown in Table $1(\mathrm{~d})$.

GPS data was obtained from Nevada Geodetic Laboratory (http://geodesy.unr.edu/index.php).

This paper select DEM data with $30 \mathrm{~m}$ resolution for external reference for simulating and eliminating the topographic phase. In the process, multiview processing is carried out to reduce the amount of data storage, improve the speed of operation, and suppress phase noise. The improved adaptive Goldstein filtering method is used to filter the generated interferogram so as to improve the quality of the interferogram [14]. The interferogram is phase unwrapped using the Delaunay Minimum Cost Flow.

\section{Result and Analysis}

For multisensor SAR datasets already processed, the annual average displacement velocity map of the Los Angeles area (see Figures 3(a)-3(d)) and time series displacement map were obtained (see Figures 4(a)-4(d)). Eight regions are found and named as regions I to VIII by order. Statistical analysis of the annual average velocity map for different periods. During 2003 to 2009, the average annual velocity of Los Angeles is $+0.35 \mathrm{~mm} / \mathrm{yr}$, the average annual velocity of the monitored pixel points is between $-78.5 \mathrm{~mm} / \mathrm{yr}$ and $+65.7 \mathrm{~mm} / \mathrm{yr}$, and the standard deviation among all pixel values is $\pm 4.6 \mathrm{~mm} /$ year. During 2009 to 2011 , the average annual velocity of Los Angeles is $+1.5 \mathrm{~mm} / \mathrm{yr}$, the average annual velocity of the monitored pixel points is between $-128.5 \mathrm{~mm} / \mathrm{yr}$ and $+161.2 \mathrm{~mm} / \mathrm{yr}$, and the standard deviation among all pixel values is $\pm 7.3 \mathrm{~mm} / \mathrm{yr}$. During 2011 to 2015 , the average annual velocity of Los Angeles is $+0.7 \mathrm{~mm} / \mathrm{yr}$, the average annual velocity of the monitored pixel points is between $-17.6 \mathrm{~mm} / \mathrm{yr}$ and $+21.3 \mathrm{~mm} / \mathrm{yr}$, and the standard deviation among all pixel values is $\pm 3.3 \mathrm{~mm} / \mathrm{yr}$. During 2015 to 2017, the average annual velocity of Los Angeles is $-0.1 \mathrm{~mm} / \mathrm{yr}$, the average annual velocity of the monitored pixel points is between $-58.7 \mathrm{~mm} / \mathrm{yr}$ and $+23.4 \mathrm{~mm} / \mathrm{yr}$, and the standard deviation among all pixel values is $\pm 3 \mathrm{~mm} / \mathrm{yr}$. It can be seen from the above data that most of the Los Angeles areas were in a stable state (slight uplift and subsidence) from 2003 to 2017, and at the same time, they proved that the processing results have good monitoring accuracy (see Figures 5(a)-5(d)).

The purpose of this experiment is to find high-risk areas with large deformation. Based on general engineering experience and experimental results, the area from $-5 \mathrm{~mm} /$ year 

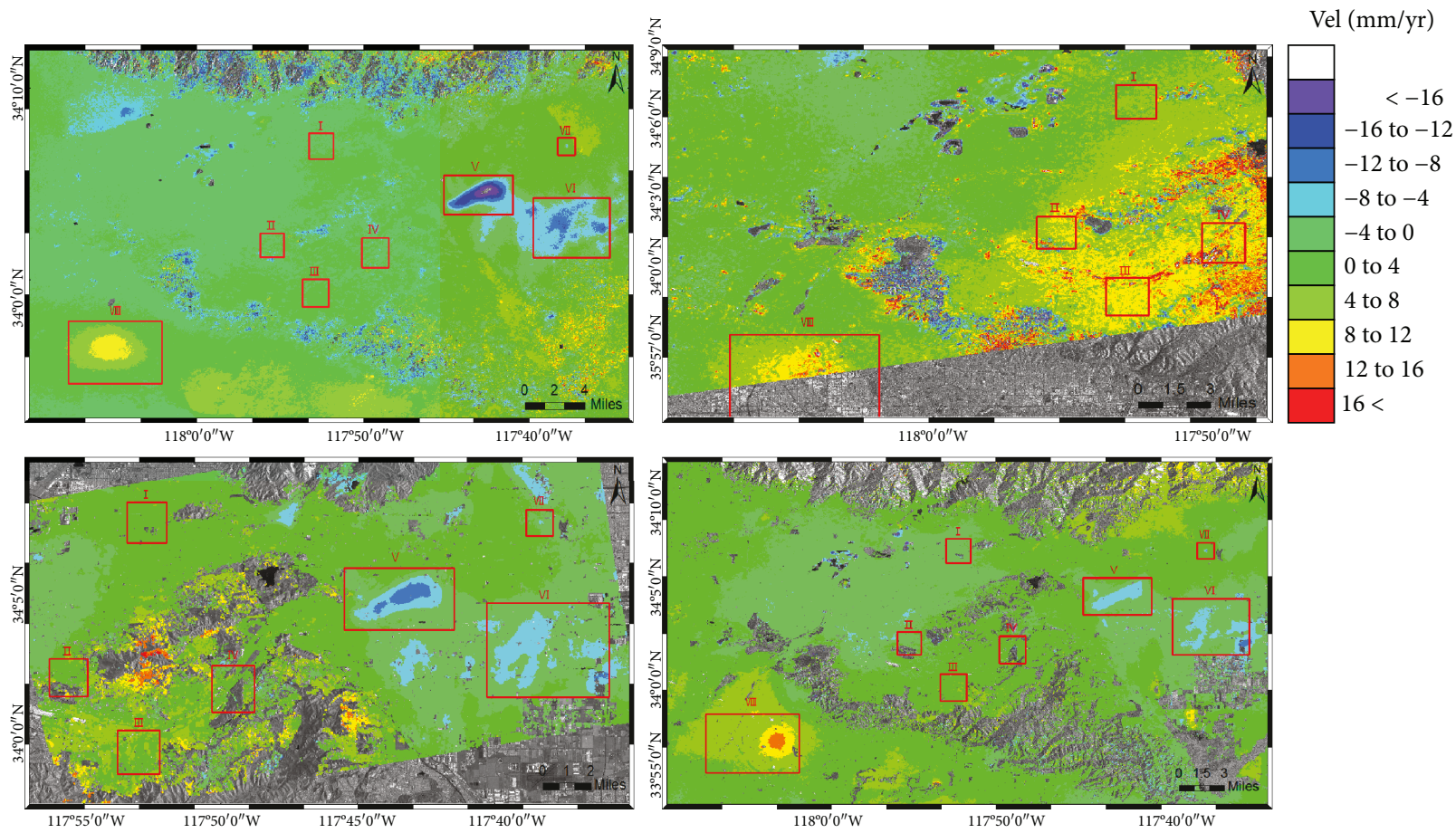

FIgURE 3: Annual average displacement velocity map from October 2003 to October 2017 by multisensor SAR datasets.

to $+5 \mathrm{~mm} /$ year was defined as a relatively stable area, such as region I-IV (see Figures 5(a)-5(d)). Regions over $\pm 5 \mathrm{~mm} /$ year are classified as potentially disaster-inducing areas, and further research is conducted such as region V-VIII (see Figures 5(e)-5(h)).

By using Google Maps contrast, it was found that stable regions I-IV are located in West Covina, Pasadena. In the stable regions I-IV, the maximum deformation is less than $25 \mathrm{~mm}$, and the annual average rate is less than $5 \mathrm{~mm} / \mathrm{yr}$ from 2003 to 2017. This shows that the area has a stable texture structure and a balanced groundwater system.

Regions V-VII are Pomona, Ontario, and Upland. From Figures 5(e)-5(g), it shows that regions V-VII have existed serious subsidence from 2003 to 2017, accumulated $-266.8 \mathrm{~mm},-105.1 \mathrm{~mm}$, and $-82.6 \mathrm{~mm}$, and the annual average velocities are $-19 \mathrm{~mm} / \mathrm{yr},-7.5 \mathrm{~mm} / \mathrm{yr}$, and $-5.9 \mathrm{~mm} / \mathrm{yr}$, respectively. What is more, the subsidence center of region $\mathrm{V}$ moves to the northeast. By consulting the data, we can see that the area is an urban area with a high population density and a large demand for water. People continue to use groundwater for their lives, resulting in an imbalance in the groundwater circulation system. As early as the 1970s, when the local government discovered the adverse consequences of overexploitation of groundwater, there was a "North-South Water Transfer" project to transfer water from Southern California to reduce groundwater use. Unfortunately, from the point of view of subsidence, the project is still insufficient because the surface still continues to settle and the rate of subsidence is not small. Based on the current results of the settling rate, the subsidence will reach the meter level within a few decades. Land subsidence is not conducive to urban construction, and it is easy to cause the foundation of the building to be unstable, resulting in the collapse of the building. When the subsidence is severe, the urban facilities will be destroyed, resulting in the shutdown, rupture, deformation, and even collapse of the engineering facilities. The ground subsidence of the road will be uneven or cracked, and the bridge will sink and deform, which will cause potential safety hazards.

Region VIII is located in Santa Fe Springs, where cumulative deformation is $+104.8 \mathrm{~mm}$, and the annual average velocities are $+5.9 \mathrm{~mm} / \mathrm{yr}$. It is speculated that the uplift of the earth's surface is related to the tectonic movement, oil extraction, and recharge. This area is close to the Whittier fault, and the vertical movement of the fault will cause the surface to rise. In the oil extraction process, water injection and recharge are usually performed to increase the extraction efficiency. The reinfusion of water injection will cause the surface to rise slowly.

\section{Result Verification}

In order to assess the accuracy of the SBAS results, we compared SBAS processing results for GPS data and Sentinel-1 data between 2015 and 2017, as shown in Figures 6(a) and 6(b). At station CIT1, the median error between GPS and SBAS data is $0.89 \mathrm{~mm}$, and the Pearson correlation coefficient is 0.892 . At station PRKD, the median error between GPS and SBAS data is $0.77 \mathrm{~mm}$, and the Pearson correlation coefficient is 0.740 . It can be shown that there is a strong consistency between the SBAS results and the GPS monitoring data, and the reliability of the experimental results is high.

In the SBAS results from the Envisat ASAR and ALOS-1 Palsar data processing, Figures 7(a) and 7(b) show time series deformation results at Pomona West Side and Rowland 

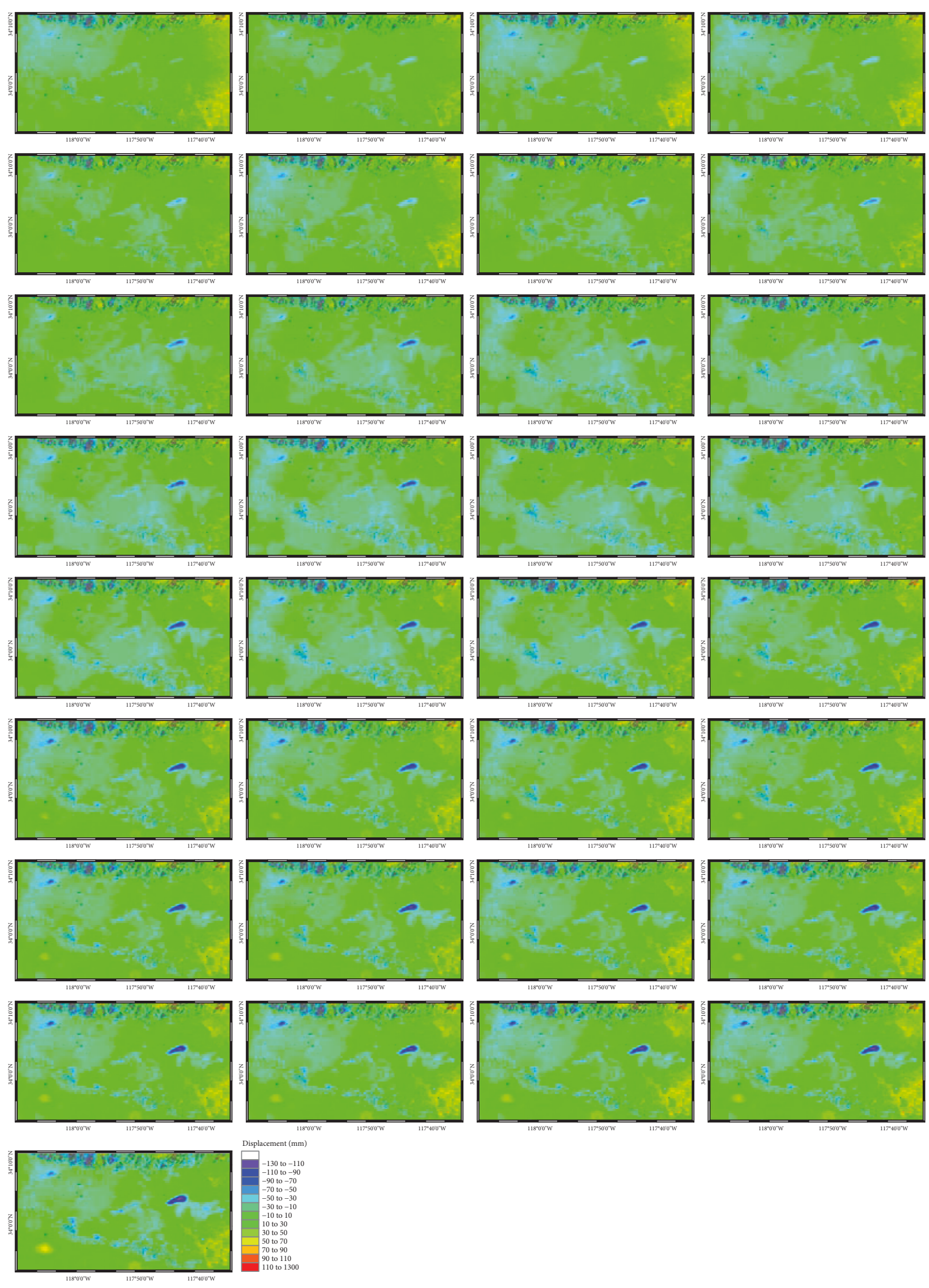

(a)

Figure 4: Continued. 

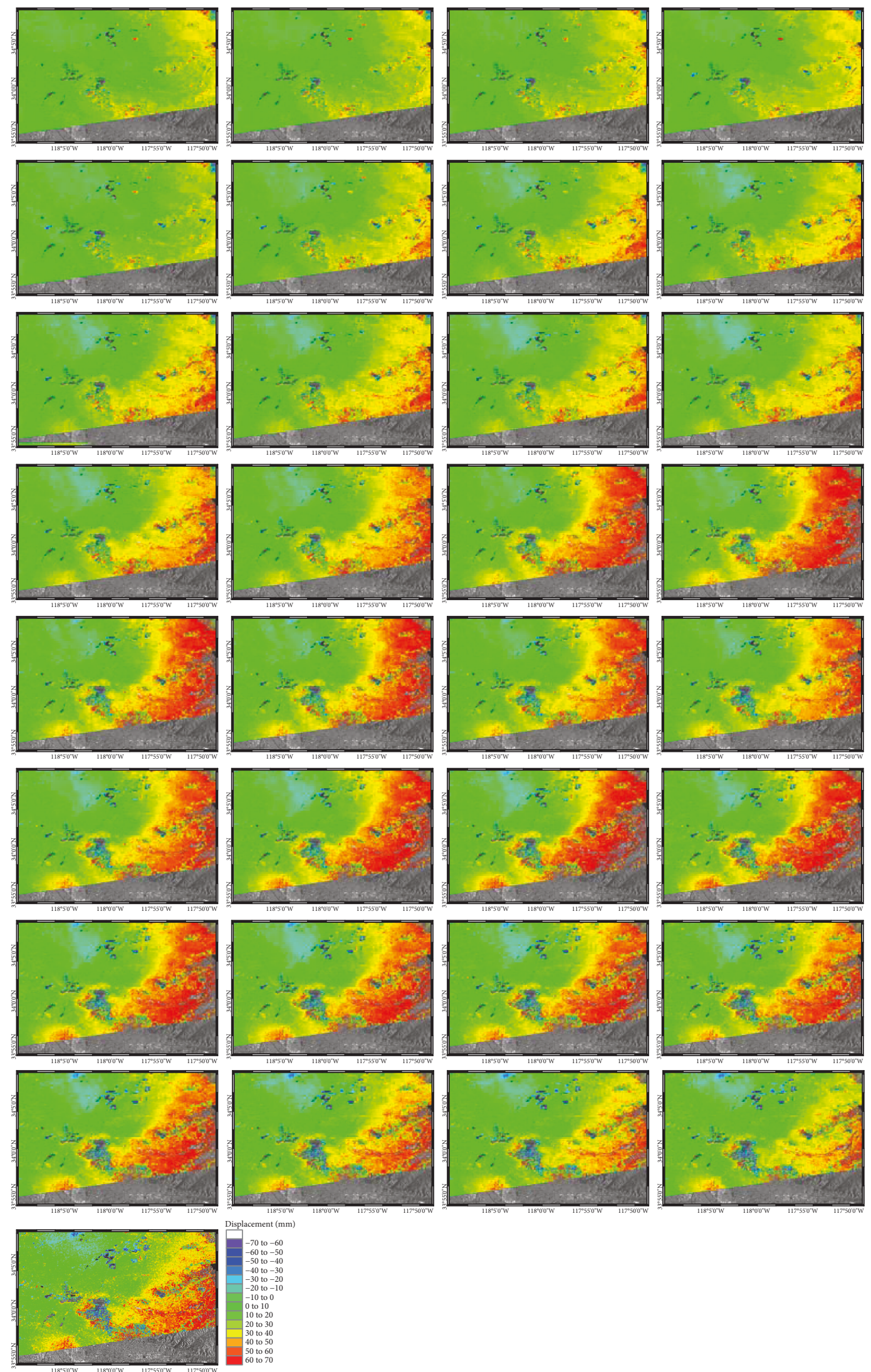

(b)

Figure 4: Continued. 

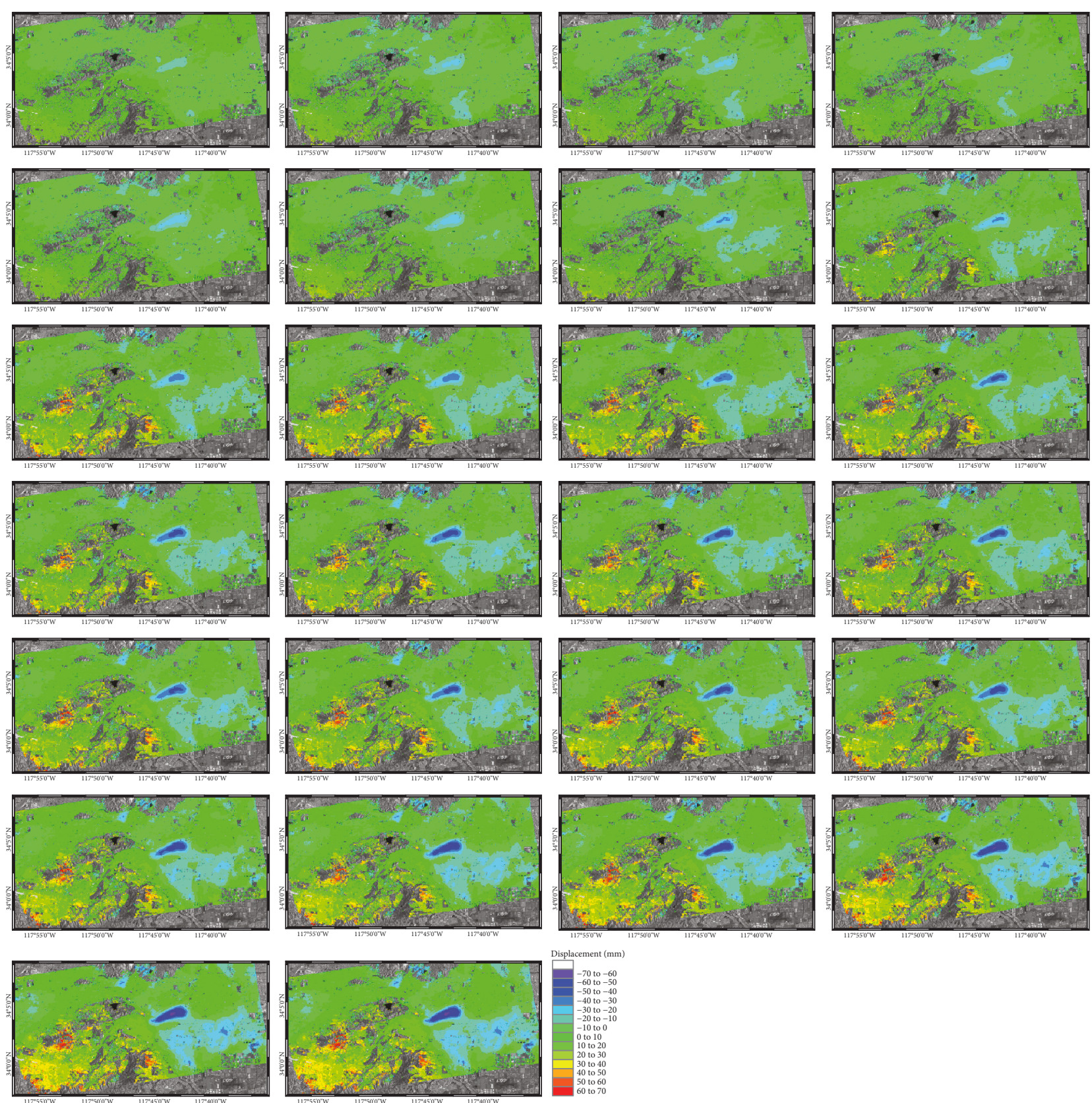

(c)

FIgURE 4: Continued. 

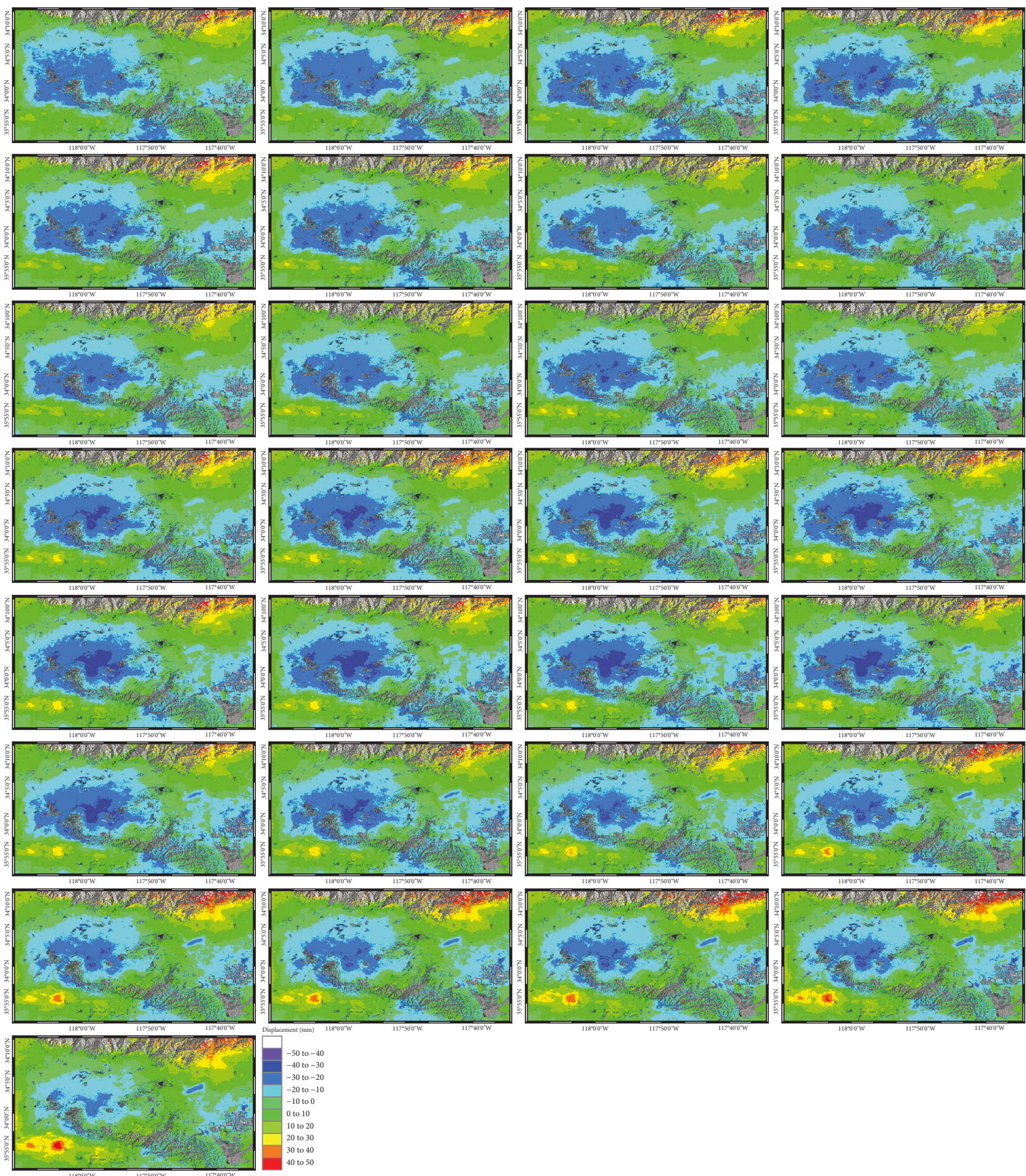

(d)

Figure 4: Result of SBAS in the study area. (a) describes the time series displacement in Los Angeles from 2003 to 2009. (b) describes the time series displacement in Los Angeles from 2006 to 2011. (c) describes the time series displacement in Los Angeles from 2011 to 2015. (d) describes the time series displacement in Los Angeles from 2015 to 2017.

Heights from December 2006 to June 2009. The medium errors were $2.70 \mathrm{~mm}$ and $1.92 \mathrm{~mm}$, and the Pearson correlation coefficients were 0.810 and 0.758 , respectively. This shows that there is a strong consistency between the monitoring results of the two data sources.
In the SBAS results from the TerraSAR-X and Sentinel-1 data processing, Figures $8(\mathrm{a})$ and 8 (b) show time series deformation results at Pomona and Ontario in 2015. The medium errors were $1.22 \mathrm{~mm}$ and $0.51 \mathrm{~mm}$ and the Pearson correlation coefficients were 0.878 and 0.981 , respectively. This also 


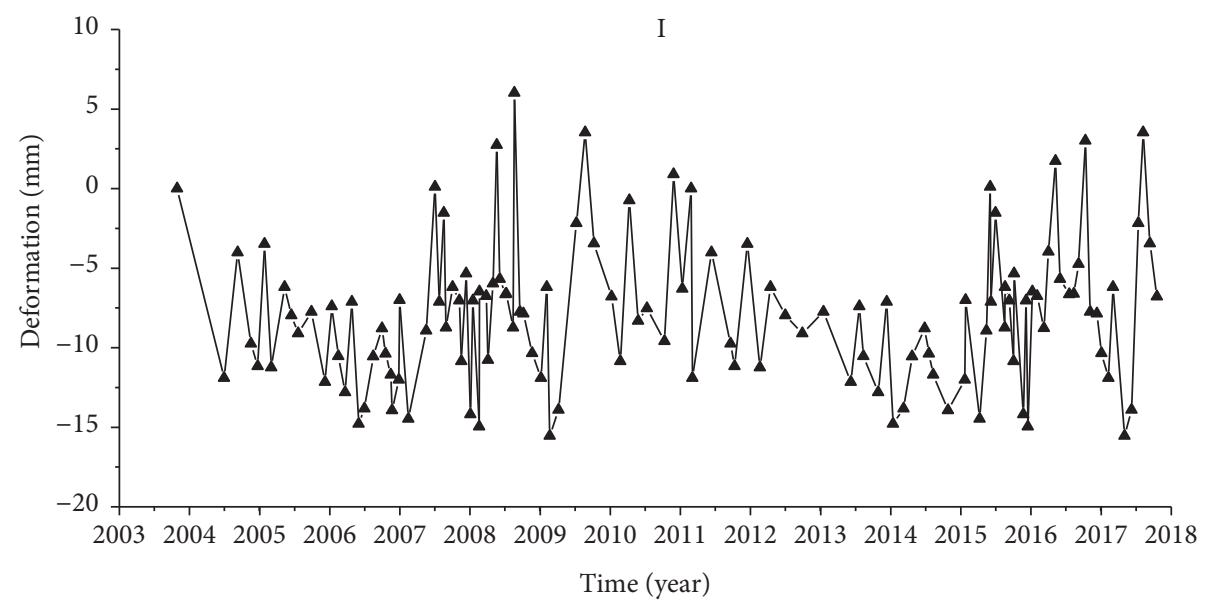

(a)

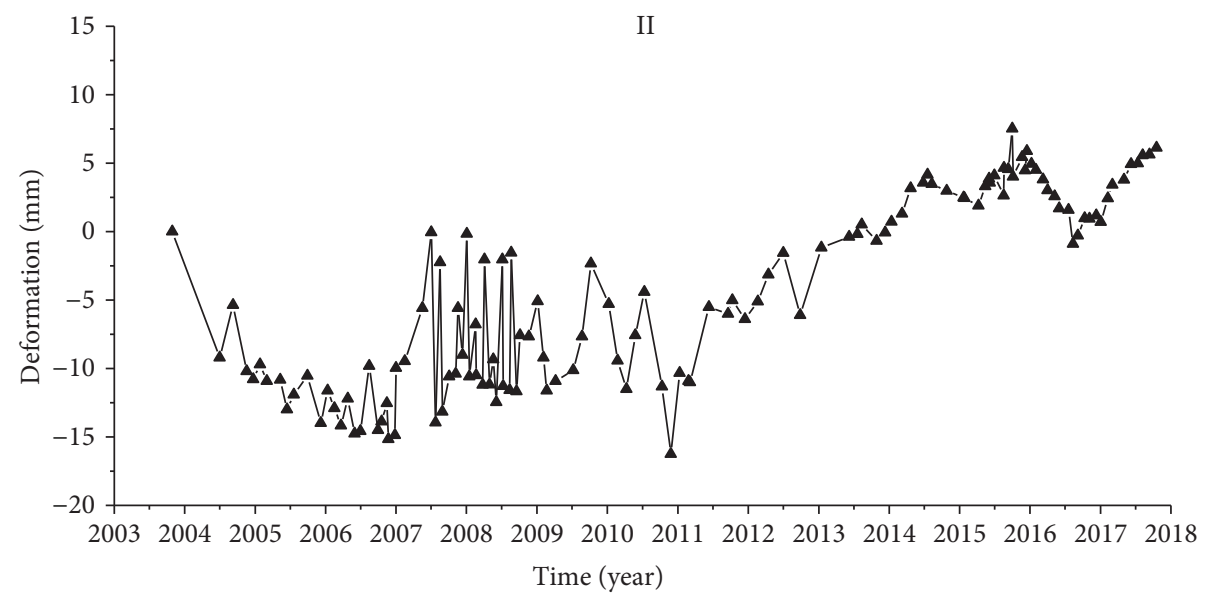

(b)

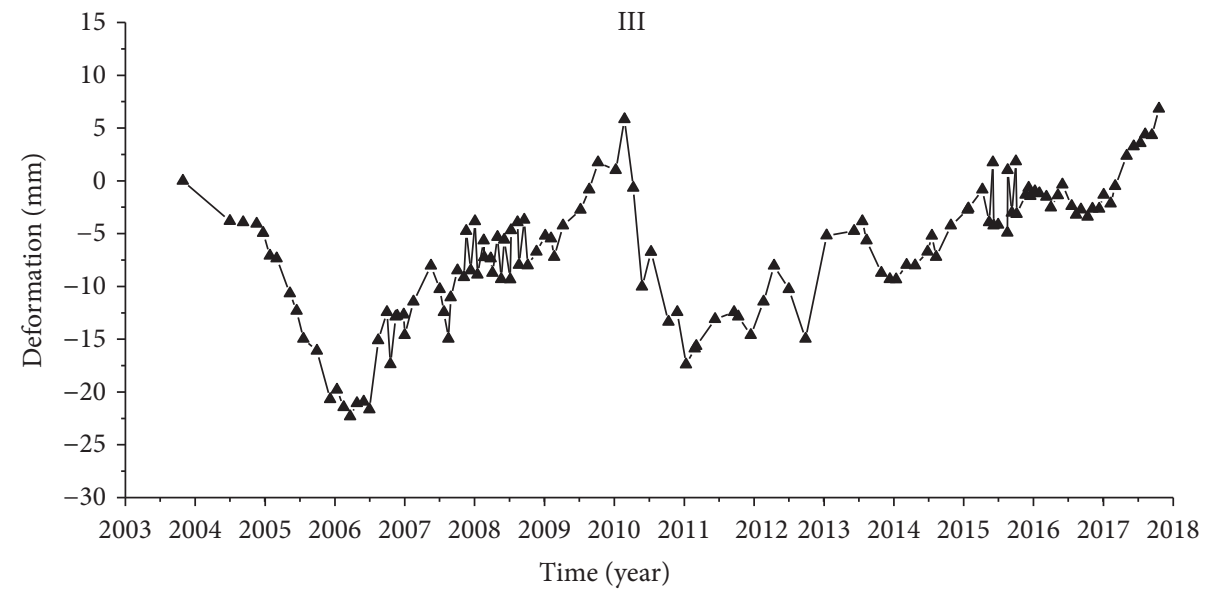

(c)

Figure 5: Continued. 


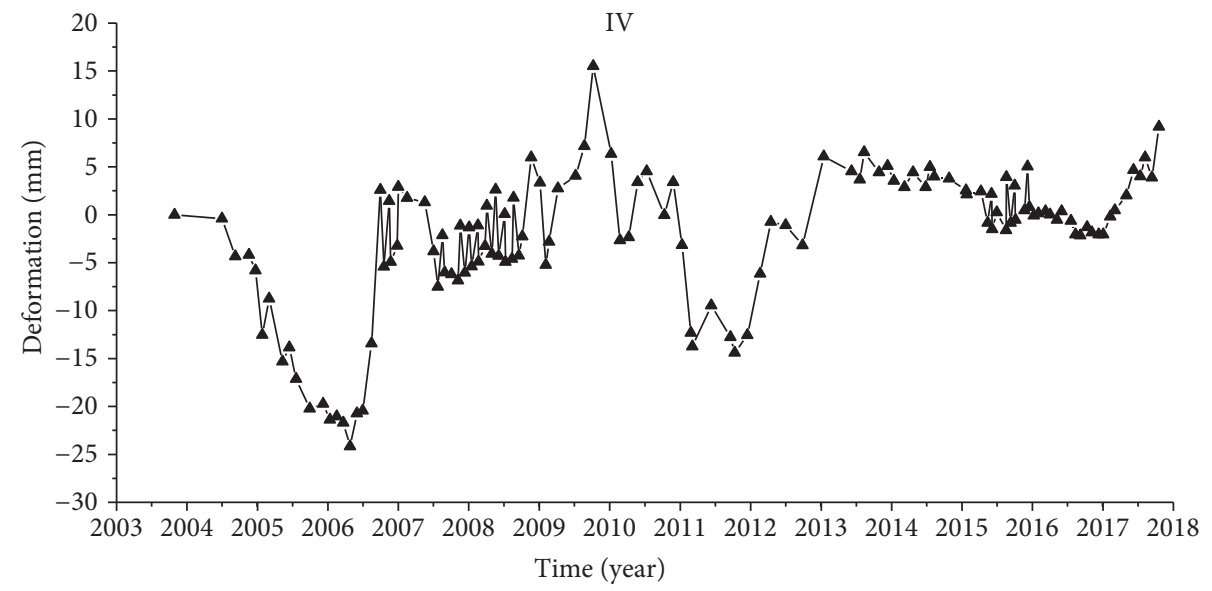

(d)

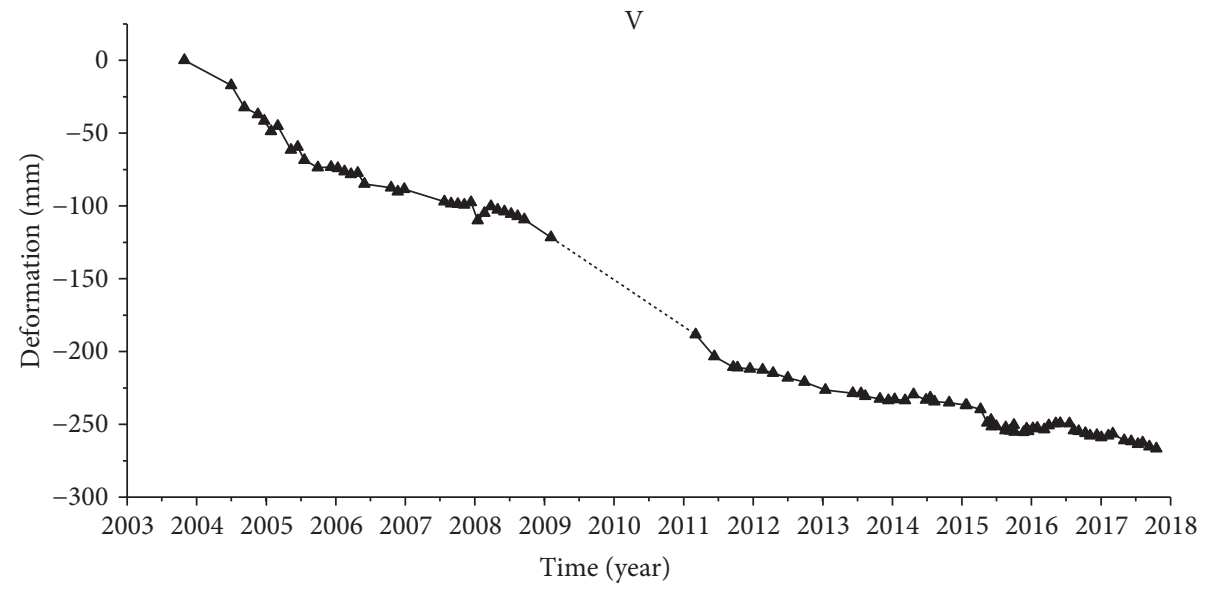

(e)

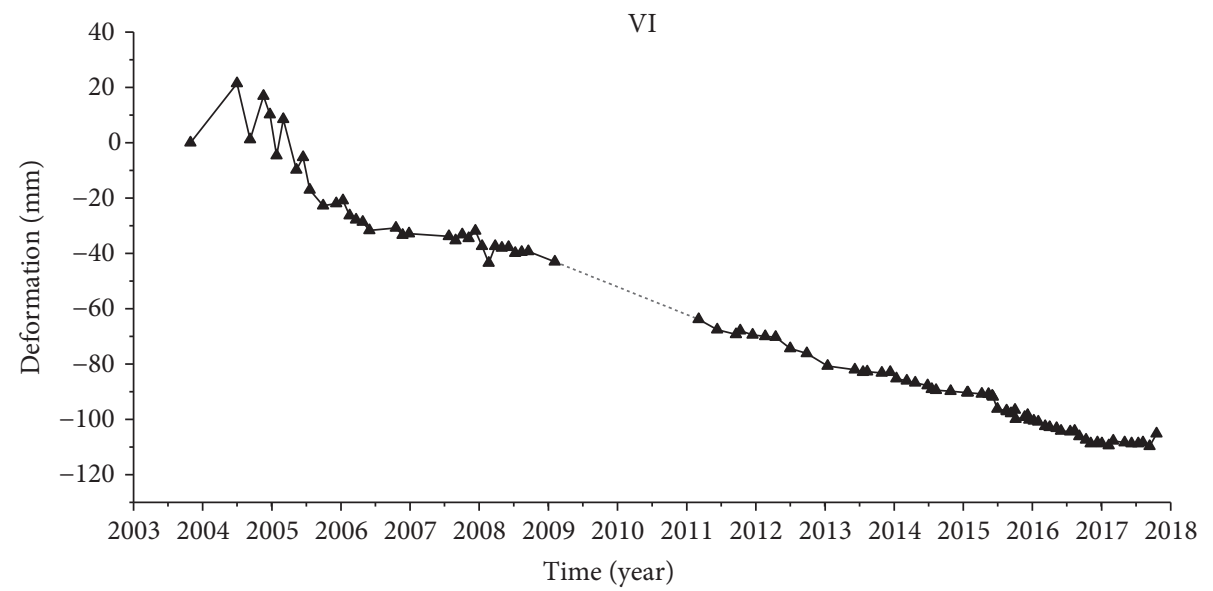

(f)

Figure 5: Continued. 


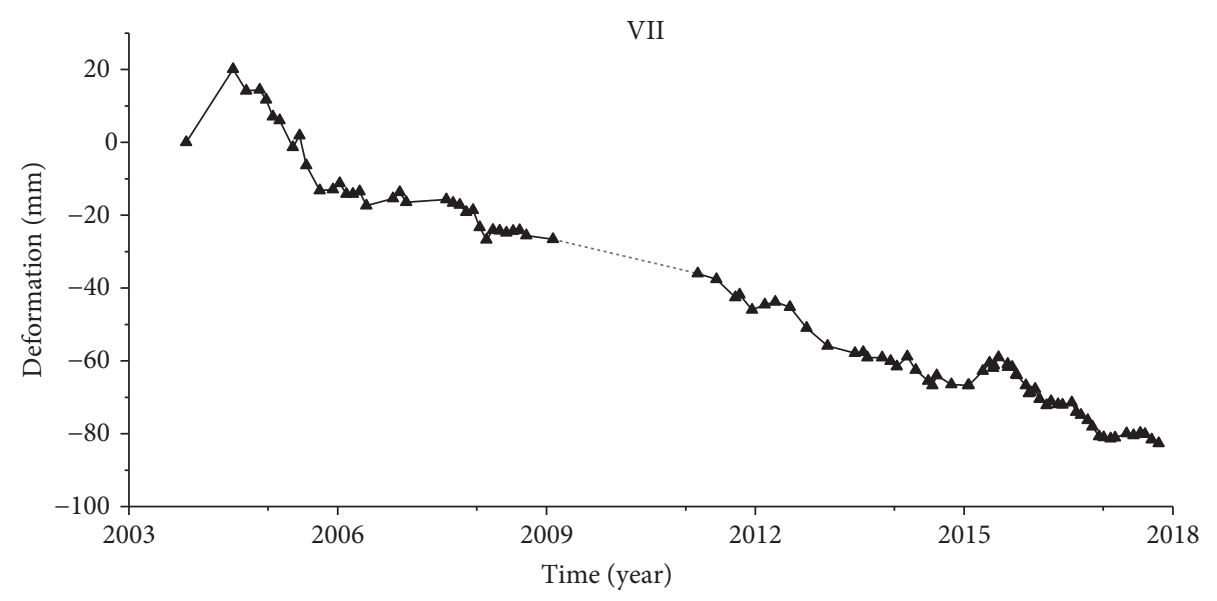

(g)

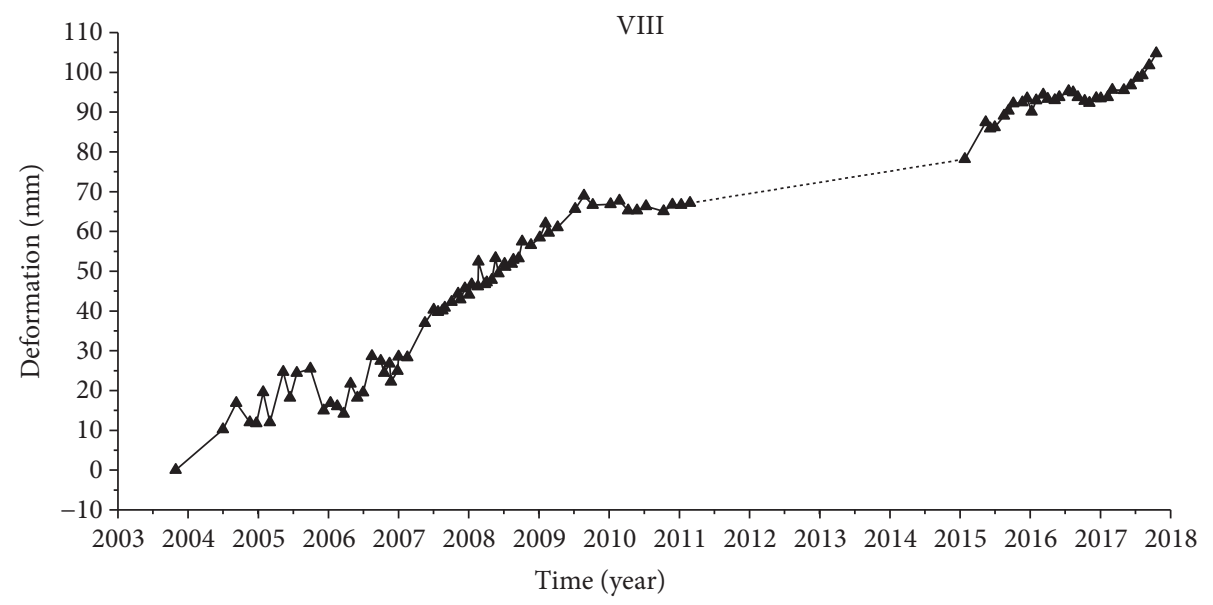

(h)

FIGURE 5: The time series displacement of region I-VIII. In Figures 5(e)-5(h), because the data coverage is not completely coincident, a part of data is missing. For the continuity of time-series analysis, the data of the dotted line in the figure is a prediction using a nonlinear curve fitting.

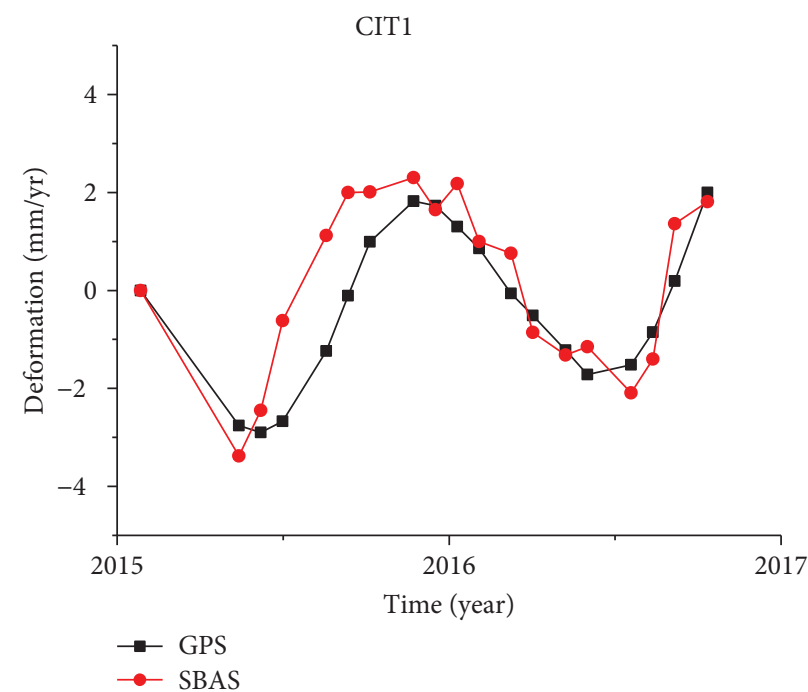

(a)

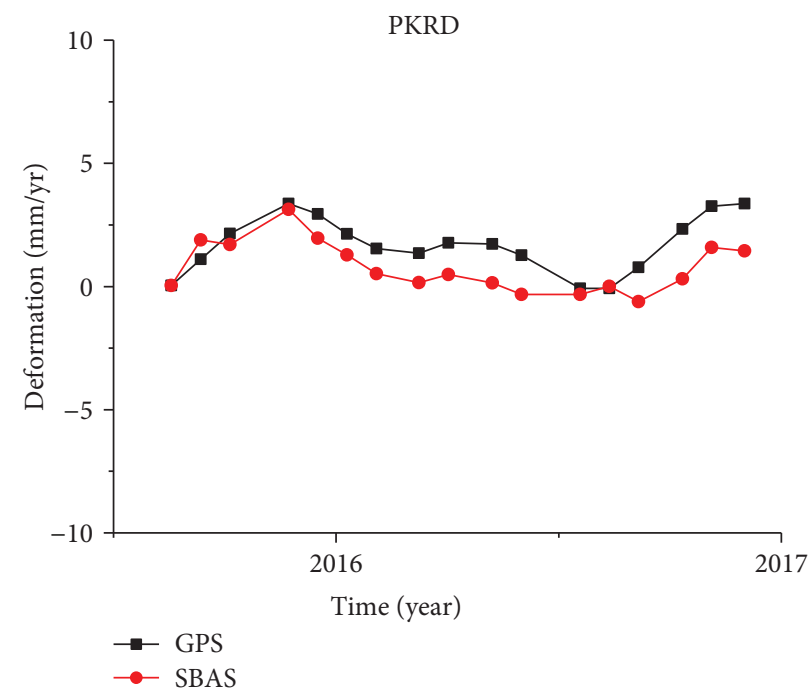

(b)

FIgURE 6: (a) CIT1 and SBAS deformation results. (b) PKRD and SBAS deformation results. 


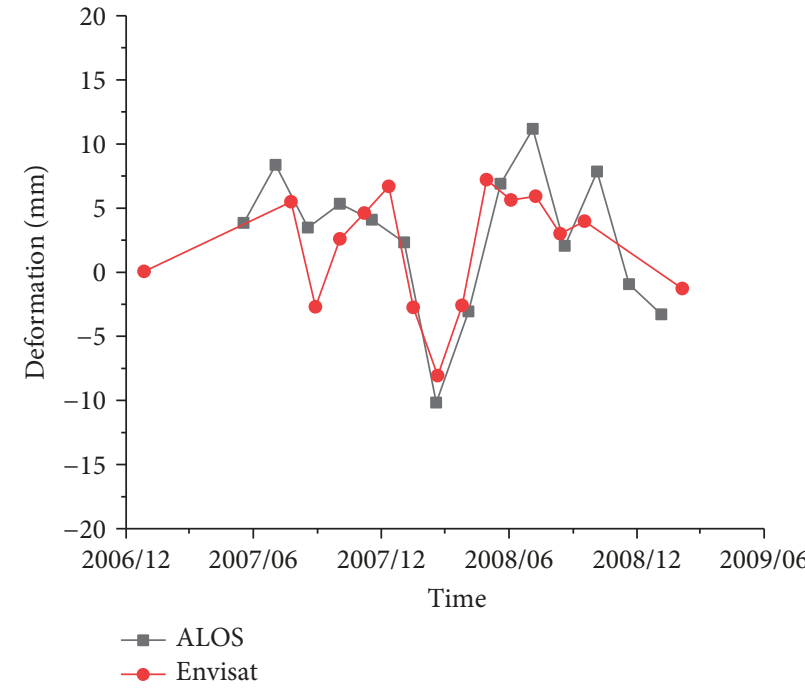

(a)

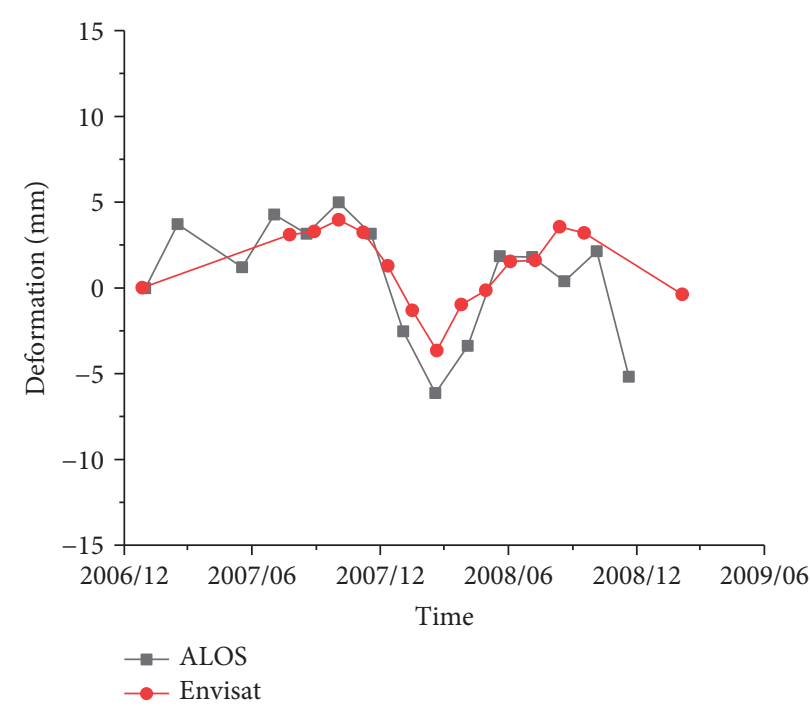

(b)

Figure 7: (a) Pomona West Side time series deformation result. (b) Rowland time series deformation result.

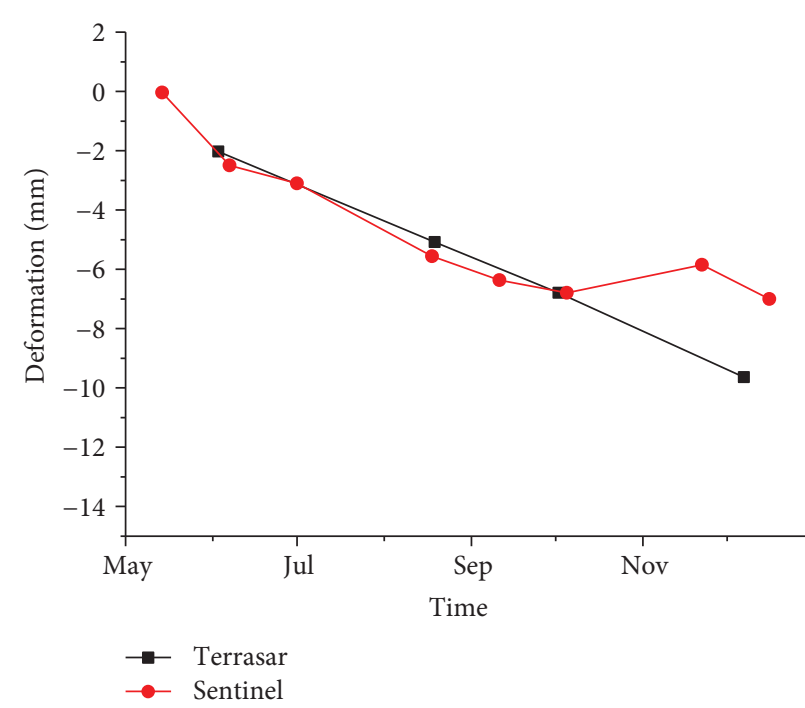

(a)

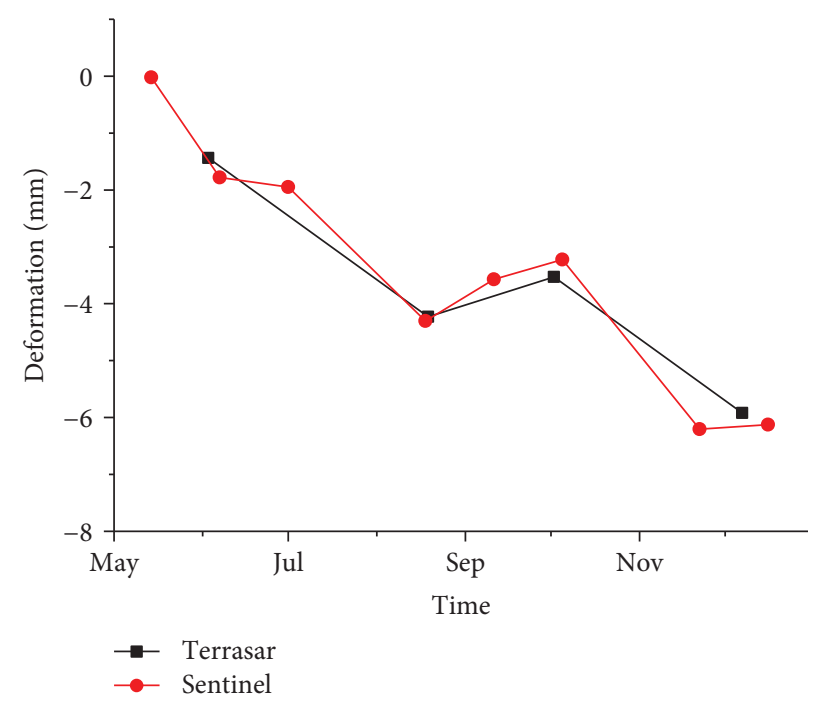

(b)

FIgUre 8: Pomona time series deformation result. (b) Ontario time series deformation result.

shows that there is a strong consistency between the monitoring results of the two data sources.

In summary, it can be seen that the results obtained by the multisensor data processing of this experiment are reliable.

\section{Conclusion}

This paper uses the SBAS technology and multisensor SAR data (Envisat ASAR, ALOS-1 Palsar, TerraSAR-X, and Sentinel-1) to perform long-term land subsidence monitoring over the Los Angeles area from 2003 to 2017. Through the sequence analysis of the deformation evolution process of the surface, uneven deformation was found. When the deformation reaches a certain level, it may cause the collapse of the building and underground pipes and wires and cause breakage and damage to other basic equipment. At the same time, by monitoring the surface variables, timely feedback to the local departments to provide relevant departments with decision-making basis. Among them, there are serious subsidences in areas V-VII, which are prone to disasters because of the overexploitation of groundwater and the need for timely prevention and control measures. Regional uplift occurred in region VII, which was presumed to be caused by water injection and tectonic movement. However, further research and analysis are needed. At the same time, the cross-validation of the deformation results obtained by multisensor data was performed, and the GPS data and Sentinel-1 deformation 
results were further compared to verify the reliability of the deformation results. In summary, the results reflect the advantages of SBAS technology and indicate that multisensor SAR data has a certain application value in urban city subsidence monitoring.

\section{Data Availability}

The DEM data used to support the findings of this study may be released upon application to the account (https://www. eorc.jaxa.jp/ALOS/en/aw3d30/data/index.htm), which can be contacted by email. The Sentinel-1 data used to support the findings of this study may be released upon application to the account (https://scihub.copernicus.eu/dhus/\#/home), which can be contacted by email.

\section{Conflicts of Interest}

The authors declare no conflict of interest.

\section{Acknowledgments}

This work was supported the National Natural Science Foundation of China (Grant Nos. 41674006 and 41704019) and by the Science and Technology Plan Project in Fujian Province (grant No. 2017Y3004). We wish to thank the Japanese Aerospace Agency (JAXA) for arranging the ALOS PALSAR data and "ALOS World 3D-30m" data. We also thank China Geological Survey for providing the GPS observation data.

\section{References}

[1] M. D. Trifunac and M. I. Todorovska, "A note on the power of strong ground motion during the January 17, 1994 earthquake in Northridge, California," Soil Dynamics and Earthquake Engineering, vol. 52, pp. 13-26, 2013.

[2] Z. Deng, Y. Ke, H. Gong, X. Li, and Z. Li, "Land subsidence prediction in Beijing based on PS-InSAR technique and improved Grey-Markov model," GIScience \& Remote Sensing, vol. 54, no. 6, pp. 797-818, 2017.

[3] Y. Wang and Q. Tian, "Application of INSAR technology in geographical situation monitoring," International Archives of the Photogrammetry, Remote Sensing \& Spatial Information Sciences, vol. 42, no. 3, pp. 1841-1847, 2018.

[4] A. Ferretti, C. Prati, and F. Rocca, "Permanent scatterers in SAR interferometry," IEEE Transactions on Geoscience and Remote Sensing, vol. 39, no. 1, pp. 8-20, 2001.

[5] B. Hu, H. S. Wang, and L. M. Jiang, "Monitoring of reclamation-induced ground subsidence in Macao (China) using PSInSAR technique," Journal of Central South University, vol. 20, no. 4, pp. 1039-1046, 2013.

[6] P. Berardino, G. Fornaro, R. Lanari, and E. Sansosti, "A new algorithm for surface deformation monitoring based on small baseline differential SAR interferograms," IEEE Transactions on Geoscience and Remote Sensing, vol. 40, no. 11, pp. 23752383, 2002.

[7] R. Lanari, F. Casu, M. Manzo, and P. Lundgren, “Application of the SBAS-DInSAR technique to fault creep: a case study of the Hayward fault, California," Remote Sensing of Environment, vol. 109, no. 1, pp. 20-28, 2007.
[8] J. Hu, X. L. Ding, Z. W. Li et al., "Vertical and horizontal displacements of Los Angeles from InSAR and GPS time series analysis: resolving tectonic and anthropogenic motions," Journal of Geodynamics, vol. 99, pp. 27-38, 2016.

[9] P. Tizzani, P. Berardino, F. Casu et al., "Surface deformation of Long Valley caldera and Mono Basin, California, investigated with the SBAS-InSAR approach," Remote Sensing of Environment, vol. 108, no. 3, pp. 277-289, 2007.

[10] P. Shanker, F. Casu, H. A. Zebker, and R. Lanari, "Comparison of persistent scatterers and small baseline time-series InSAR results: a case study of the San Francisco Bay area," IEEE Geoscience and Remote Sensing Letters, vol. 8, no. 4, pp. 592-596, 2011.

[11] R. Lanari, P. Lundgren, M. Manzo, and F. Casu, "Satellite radar interferometry time series analysis of surface deformation for Los Angeles, California," Geophysical Research Letters, vol. 31, no. 23, 2004.

[12] R. Lanari, F. Casu, M. Manzo et al., "An overview of the small baseline subset algorithm: a DInSAR technique for surface deformation analysis," Pure and Applied Geophysics, vol. 164, no. 4, pp. 637-661, 2007.

[13] R. Lanari, O. Mora, M. Manunta, J. J. Mallorqui, P. Berardino, and E. Sansosti, "A small-baseline approach for investigating deformations on full-resolution differential SAR interferograms," IEEE Transactions on Geoscience and Remote Sensing, vol. 42, no. 7, pp. 1377-1386, 2004.

[14] M. Manzo, Y. Fialko, F. Casu, A. Pepe, and R. Lanari, "A quantitative assessment of DInSAR measurements of interseismic deformation: the southern San Andreas fault case study," Pure and Applied Geophysics, vol. 169, no. 8, pp. 1463-1482, 2012. 


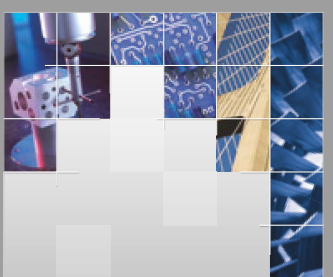

\section{Enfincering}
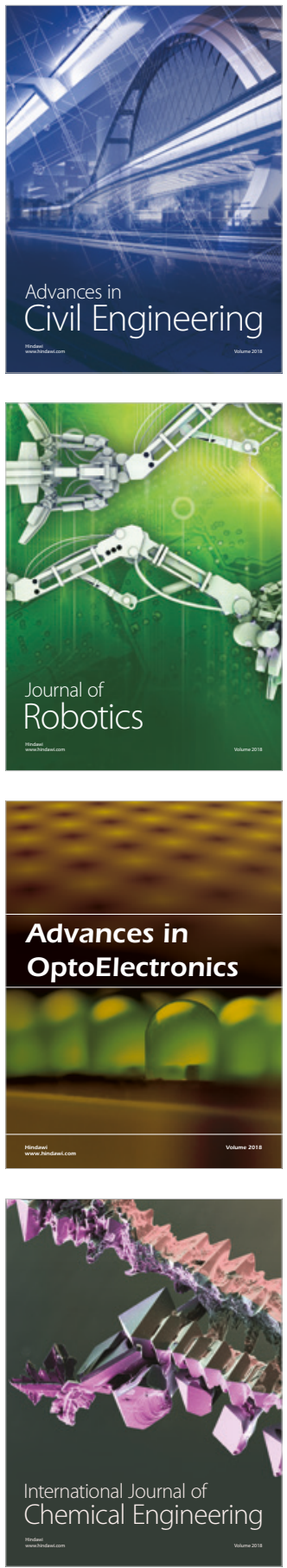

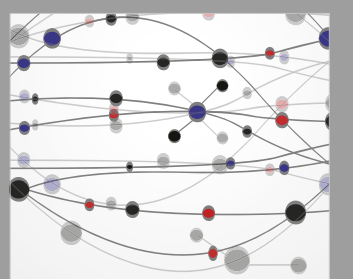

\section{Rotating \\ Machinery}

The Scientific World Journal

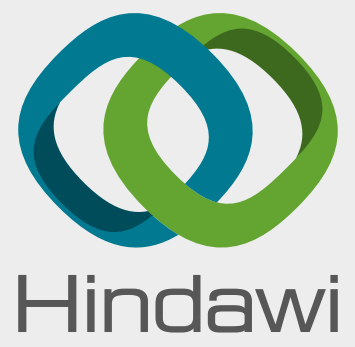

Submit your manuscripts at

www.hindawi.com
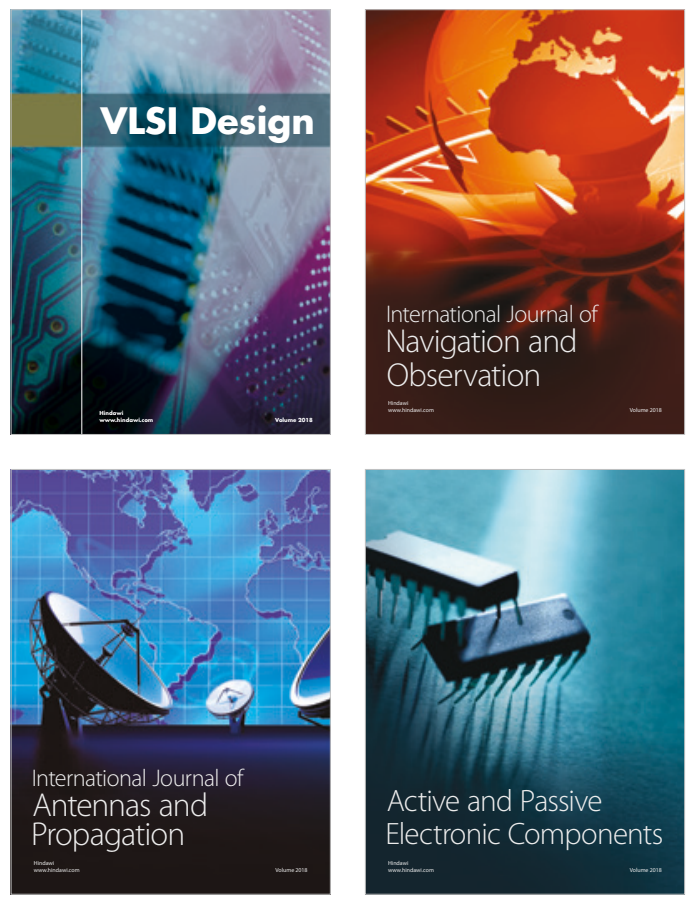
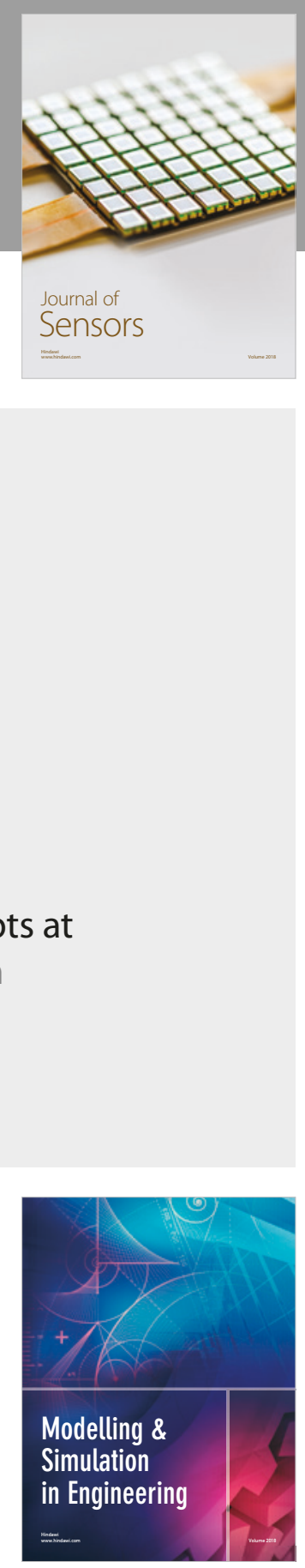

\section{Advances \\ Multimedia}
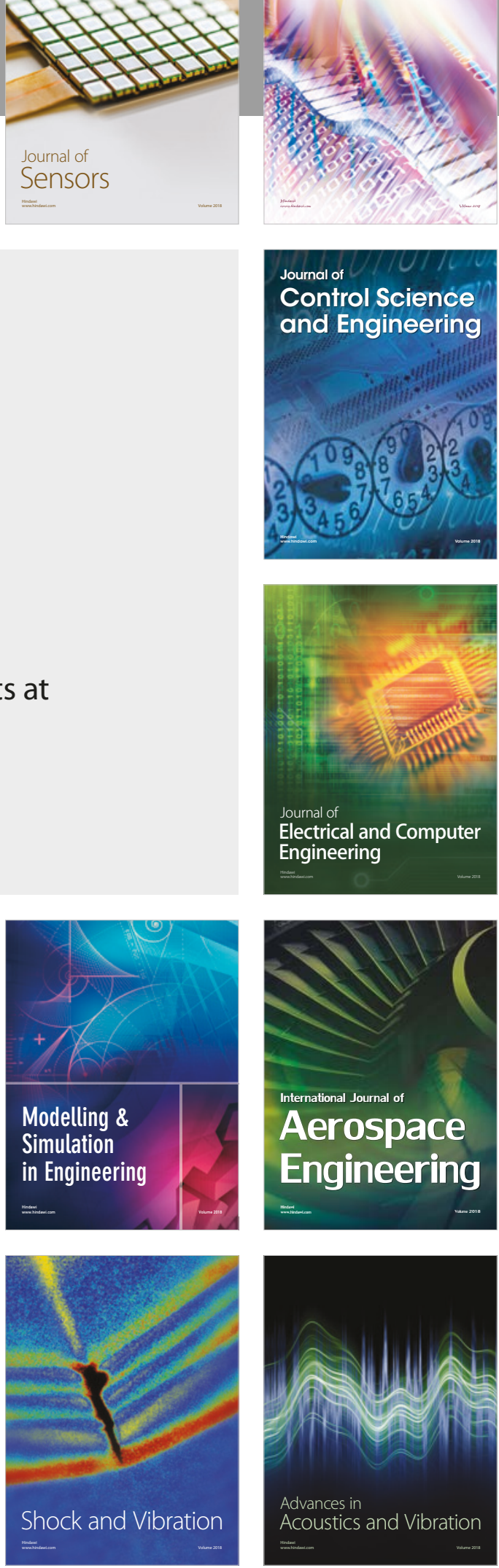